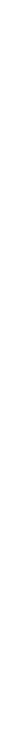

\title{
EDITORIAL: MIGUILIM, UM INSTRUMENTO DE DIVULGAÇÃO CIENTÍFICA NA ÁREA DE LETRAS/LINGUÍSTICA
}

EDITORIAL: MIGUILIM, A SCIENTIFIC INSTRUMENT DISCLOSURE IN FIELD OF LANGUAGES, LITERATURES AND LINGUISTICS

Francisco de Freitas LEITE Edson SOARES MARTINS

Newton de Castro PONTES Luís André Bezerra de ARAÚJO NETLLI, Brasil

Texto integral

Neste volume 4, número 1 (2015) da Miguilim - Revista Eletrônica do Netlli, publicamos cinco trabalhos divididos em três seções: Estudos linguísticos, Estudos literários e Resenhas. 
A primeira seção traz apenas um trabalho: Ideologia e transitividade no discurso do Papa Francisco, de Vinícius Nicéas do Nascimento e Maria Sirleidy de Lima Cordeiro (UFPE), em que é apresentada uma análise dos processos mentais presentes nos pronunciamentos do Papa Francisco proferidos durante a Jornada Mundial da Juventude 2013, com base na Linguística Sistêmico-Funcional e na Análise Crítica do Discurso.

A segunda seção traz três trabalhos: (i) Memórias de um diário fotográfico: $O$ Livro das emoções, de Mauro Sergio Apolinário (UFRJ), em que são tratadas algumas questões pertinentes ao estudo da fotografia como questão literária e paralelamente é considerado O livro das emoções, de João Almino, principalmente acerca do nascimento da imagem fotográfica no texto literário, visualizando não imagens prontas, mas sim imagens vindas das janelas da alma; (ii) $A$ arte literária $e$ suas nuances: do discurso teórico às metamorfoses da expressão, de Tito Eugênio Santos Souza (UFPE), em que, além de uma discussão em torno de alguns conceitos fundamentais para o campo de investigações da teoria da literatura, são traçadas breves considerações sobre a obra literária no que concerne ao seu processo de criação, percepção estética e "espaço de fruição", conforme Roland Barthes; (iii) $O$ duplo em "Tigrela", de Lygia Fagundes Telles, de Rebecca Demicheli Sampaio (UCS), em que é investigada a problemática do duplo no conto Tigrela, na medida em que se evidencia um embate entre Romana e a tigresa pela apropriação de seu espaço.

A terceira seção traz apenas a resenha, de autoria de Vicentônio Regis do Nascimento Silva (UEL) e Adriana Jesuíno Francisco (UNESP), do livro Tributo a Moacyr Scliar, organizado por Zilá Bernd, Maria Eunice Moreira e Ana Maria Lisboa de Mello e publicado, em 2012, pela EDIPUCRS (Porto Alegre).

Aqui, além de estudos e pesquisas, os leitores encontrarão os esforços de editores, autores, avaliadores e técnicos que mantêm a Miguilim - Revista Eletrônica do Netlli em atividade desde 2012, a despeito de todas as dificuldades e adversidades que se nos apresentam.

É, porém, com muito orgulho que, de uma pequena e jovem universidade aos pés da Chapada do Araripe, no interior do Ceará, mantemos este ideal de a Miguilim - Revista Eletrônica do Netlli ser um instrumento de divulgação científica na área de Letras/Linguística.

\section{Para citar este artigo}

LEITE, Francisco de Freitas et al. Editorial: Miguilim, um instrumento de divulgação científica na área de Letras/Linguística. Miguilim - Revista Eletrônica do Netlli, Crato, v. 4, n. 1, p. 01-03, jan.-abr. 2015.

\section{Os autores}

Francisco de Freitas Leite é doutor em Linguística (PROLING/UFPB - 2014), mestre em Linguística (PROLING/UFPB - 2009), especialista em Ensino de Língua Portuguesa (URCA - 1999) e graduado em Letras (URCA - 1998). Atualmente é 
professor adjunto I da Universidade Regional do Cariri-URCA, coordenador na URCA do DINTER em Linguística - UFC/URCA, pesquisador do Núcleo de Estudos de Teoria Linguística e Literária NETLLI, pesquisador do Grupo de Pesquisas em Estudos Clássicos e Linguísticos GREC, editor-geral da Miguilim - Revista Eletrônica do Netlli e editor-adjunto da Macabéa - Revista Eletrônica do Netlli. Tem experiência na área de Letras, com ênfase em Linguística, Língua Portuguesa e Língua Latina, atuando principalmente nos seguintes temas: linguística histórica, história da língua portuguesa, poesia brasileira e teoria/análise dialógica do discurso.

Edson Soares Martins possui graduação (1996), mestrado (2001) e doutorado (2010) em Letras pela Universidade Federal da Paraíba (PPGL). Concluiu estágio pós-doutoral junto ao PROLING-UFPB. Atualmente é Professor Adjunto de Literatura Brasileira, na Universidade Regional do Cariri (URCA). Tem experiência na área de Literatura, com ênfase em Literatura Brasileira, atuando principalmente nos seguintes temas: literatura brasileira, poesia, narrativa moderna e contemporânea, romances de Clarice Lispector e Osman Lins e psicanálise. Também manifesta crescente interesse pelas literaturas africanas. Editor-geral de Macabéa - Revista Eletrônica do Netlli.

Newton de Castro Pontes é doutor em Teoria da Literatura pela Universidade Federal de Pernambuco (UFPE). Licenciou-se em Letras pela Universidade Regional do Cariri (URCA) e concluiu mestrado em Literatura e Interculturalidade pela Universidade Estadual da Paraíba (UEPB). Atualmente, é professor de Teoria da Literatura na URCA. Desenvolve pesquisas nas áreas de Teoria do Conto, Crítica Textual e Sociologia Aplicada à Literatura. É membro do Núcleo de Estudos em Teoria Linguística e Literária (NETLLI) e dos conselhos editoriais da Macabéa Revista Eletrônica do NETLLI e da Miguilim - Revista Eletrônica do NETLLI.

Luís André Bezerra de Araújo possui graduação em Letras pela Universidade Regional do Cariri (2003), mestrado em Letras pela Universidade Federal da Paraíba (2009) e doutorado em Letras pela Universidade Federal da Paraíba (2013). Atualmente é tutor à distância - UFPB Virtual da Universidade Federal da Paraíba. Tem experiência na área de Letras, com ênfase em Literatura Brasileira, Canção e Cinema. 